\title{
Effect of Unitary Soil Tillage Energy on Soil Aggregate Structure and Erosion Vulnerability
}

\author{
Tomasz Wojciechowski' ${ }^{1}$ Andrzej Mazur ${ }^{2 *}$, Andrzej Przybylak' ${ }^{1}$ Jarosław Piechowiak \\ 1 Institute of Biosystems Engineering, Poznań University of Life Sciences, ul. Wojska Polskiego 50, 60-637 Poznań, \\ Poland \\ 2 Department of Environmental Engineering and Geodesy, University of Life Sciences in Lublin, \\ ul. Leszczyńskiego 7, 20-069 Lublin, Poland \\ * Corresponding author's e-mail: amazur70@op.pl
}

\begin{abstract}
The integrated soil tillage developed in the Institute of Biosystem Engineering is based on a single pass of basic tillage, secondary tillage and sowing or planting. The integrated soil tillage enables to achieve a relatively high mechanical strength of the soil. An important element of the technology is the use of tillage roller sets which significantly influence the obtained aggregate structure and its eolic resistance. The aim of the study was to determine the influence of roller speed under various soil moisture conditions on the aggregate structure of the arable soil layer. The research was carried out on the production field in Dziećmierowo, Wielkopolska Voivodeship, Poland, on medium soil with the mechanical composition of light clay. During the research, cultivation sets with two units of Campell + Croskill platelet and studded rollers were used. For two actual soil moisture levels and five speeds within the range of $3-7 \mathrm{~km} / \mathrm{h}$, the influence of unit tillage energy at three levels of the cultivating layer $(0-5 \mathrm{~cm}$, $5-10 \mathrm{~cm}$ and $10-15 \mathrm{~cm}$ ) was analyzed on the aggregate structure of soil and the content of aggregates with the highest resistance to wind erosion. The results of the work lead to the conclusions that it is possible to use the working speed and overloading of rollers set in integrated soil tillage trailer to manipulate the process of forming an optimal, erosion-resistant soil layer. However, it should be pointed out that for even very similar types of roller sets, the process control under different soil moisture conditions may be different and require an individual test.
\end{abstract}

Keywords: integrated soil tillage, unitary tillage energy, soil erosion, soil aggregates

\section{INTRODUCTION}

In the cultivation of plants, soil tillage is the most energy-intensive process. Simplified tillage technologies, such as reduced tillage, no-tillage, strip-till, allow obtaining lesser energy consumption, but also to protect soils from wind, water and tillage erosion, reduce damage to the soil structure, as well as decrease the time for seedbed preparation, fertilization and protection [Moraru et al. 2012; Tabatabaeefar et al. 2009]. However, simplified technologies cannot be adopted under all conditions and at every farm [Pabin et al. 2008]. Adopting tillage simplifications on polyfractional soils with low natural porosity and low mechanical strength of aggregate structure, such as clay sands, often found in the Wielkopolska region in Poland is the most difficult. Difficulties in the adaptation of simplified technologies are also shown by estimates, which indicate that in Poland $60 \%$ of arable land is still cultivated with conventional technologies. Therefore, it seems important to develop new solutions for conventional soil tillage technologies, which will allow achieving better economic and soil-improving effects [Czajka et al. 2010].

The integrated soil tillage (IST) technology developed in the Institute of Biosystem Engineering, Poznań University Life Science, is based on a single pass of basic tillage, secondary tillage and sowing or planting [Podsiadłowski and Hagen 2000]. The IST allows obtaining a relatively high mechanical strength of the soil. An important element of the technology is the use of tillage roller 
sets which significantly influence the obtained aggregate structure and its eolic resistance. Integrated soil tillage provides additional benefits:

- the wheels of the tractor do not compact the soil that has previously been aggregated;

- the elimination of tracks allows for relatively free shaping of the overall soil porosity of the arable layer,

- limiting the energy input per unit of cultivation and performing it under the conditions of usually medium humidity, allows obtaining relatively high mechanical strength of the resulting aggregate structure [Podsiadłowski 2005];

- Improves the soil capillary rising conditions and allows for a significant increase in the crops yield, especially root crops and vegetables [Walkowiak et al. 2017].

The effect of each agrotechnical operation is the process of transferring energy to the soil allowing for its mixing, crushing, loosening or compaction. In the papers which describe the energy balance of the crop production, its energy efficiency, it is presented as a relation between the energy introduced into the system (energy of the crop, energy of fertilizers, energy of plant protection products, energy of human work) and energy as output (energy of grain, energy of digestion). In these works, the energy of the crop is expressed in two ways: per unit of product (Mj kg-1) [Vural and Efecan 2012] or, less frequently, per unit of cultivated area $\left(\mathrm{kJ} \mathrm{m}^{-2}\right)$. The calculation of unitary energy of tillage is usually an approximation. In the discussion above, attention is drawn to the effects of soil tillage on their productivity, and less frequently, to their soil-protective effect in relation to the unitary energy inputs. The unitary tillage energy $\left(\mathrm{E}_{\mathrm{U}}\right.$, ) is the difference between the energy produced by the tractor's engine and the energy used to till and overcome the mechanical resistance of a tractor [Krysztofiak and Podsiadlowski 1998]. An agricultural tractor interacts with the soil with an energy of 4 to $10 \mathrm{~kJ} \mathrm{~m}^{-2}$, the soil transition from a cohesive to an aggregate structure, which takes place e.g. during ploughing, requires a unit energy input of 9 to $15 \mathrm{~kJ} \mathrm{~m}^{-2}$, while the tools for secondary tillage interact with an energy of 1 to $3 \mathrm{~kJ} \mathrm{~m}^{-2}$ [Podsiadłowski 1995, Rusu 2014].

The opportunity to dynamically modify the energy of cultivation in relation to the spatial variability of the soil tillage layer can potentially become an effective tool for precision farming technologies [Neményi, Mesterházi, and Milics 2006]. However, this requires determining whether and how the unit energy of cultivation can affect, for example, the aggregate structure of the tilled soil. Therefore, the aim of the study was to determine the influence of unitary tillage energy, controlled by speed and type of roller, under various soil moisture conditions on the aggregate structure of the soil arable layer.

\section{MATERIALS AND METHODS}

The research was carried out on the production 2 ha field in Dziećmierowo, Wielkopolskie Voivodeship, Poland, on medium soil with mechanical composition of light clay, with organic matter content $1.2 \%$.

In two terms, to obtain two actual soil moisture levels (W1, W2), the treatment was carried out with a set for integrated soil tillage. The working set consisted of a $140 \mathrm{hp}$ Case Maxxum tractor (weight of $4950 \mathrm{~kg}$ ) with attached cultivation set consisting of four furrow plough (Unia Ibis, working width $2 \mathrm{~m}$, weight $1015 \mathrm{~kg}$ ) with a rollers section at in two variants: (a) Campbell+Croskill platelet, weighing $1150 \mathrm{~kg}$, and (b) Campbell+Croskill stugged, weighing $1400 \mathrm{~kg}$. The Croskill staged type differs from the platelet type also in the increased distance between the rings, and in the wedgeshaped rather than cuboid fingers (tiles). The used tillage set is adapted to the integrated tillage technology and, for these surveys, the row seed drill segment has been dismounted. The variation of the unitary rollers tillage energy $\left(\mathrm{E}_{\mathrm{ur}}\right)$ was obtained by changing the speed, from 3 to $7 \mathrm{~km} \mathrm{~m}^{-2}$.

The test was performed in a block design with three repetitions. For each of the unit energy levels, two rollers type and two soil moisture levels, the aggregate composition was analysed at three tillage depths $0-5,5-10$ and $10-15 \mathrm{~cm}$. The soil samples for a quantitative analysis of the aggregate structure were taken from the topsoil using the methodology developed by Skidmore [1992] For half-kilogram averaged soil samples, from each layer, after drying to air dry moisture, the percentage fraction of aggregates was determined with the dry sifting method on sieves with dedicated mesh diameter, obtaining seven aggregates size classes, i.e. $\varnothing>6.3 \mathrm{~mm}$; Ø 6.3-3.15 mm; Ø 3.15-2 mm; Ø 2-1 mm; 
$\varnothing$ 1-0.5 mm; Ø $0.5-0.25 \mathrm{~mm}$ and $\varnothing<0.25 \mathrm{~mm}$. This corresponds to different classes of aggregates from the highest to the lowest resistance to wind and water erosion.

The final statistical analysis and discussion was conducted on the percentage content of the analysed aggregates groups as a function of the change in the total unitary tillage energy (EUT), roller unitary tillage energy (EUR), plough unitary tillage energy (EUP) and tractor unitary tillage energy (EUTR) were calculated by means of the STAPOD programme [Krysztofiak and Podsiadlowski 1998]. The statistical significance of differences was determined using the Student's test at the confidence level $\mathrm{P}=0.05$.

\section{RESULTS AND DISCUSSION}

The machine set used in the research with two types of roller-set enabled obtaining of five levels of total unitary tillage energy $\left(\mathrm{E}_{\mathrm{UT}}\right)$, from 10.2 to $12.5 \mathrm{kJm}^{-2}$, and rollers unitary tillage energy $\left(E_{U R}\right)$, from $0: 79$ to $0.93 \mathrm{~kJ}^{-2}$ (Fig. 1.) for each roller-type set. The obtained values did not exceed the value of $2 \mathrm{~kJ} \cdot \mathrm{m}^{-2}$ (above which soil aggregates may be destroyed and the number of aggregates with higher erodability increases) and were agreement with the recommendations from other studies [Podsiadłowski and Hagen 2000].

The average percentage values obtained in this work for the analysed classes of soil aggregates, roller-set types, tillage levels and soil moisture are presented in Table 1. The statistical analysis showed the effect of roller-set type and tillage moisture on the content of aggregates in the given classes; however, the statistically significant differences occurred only in some of them and concerned mainly the aggregates of the largest and smallest of top soil layers. Regardless of the examined factors levels in the tillage process aggregates of different size were formed; however, the largest number of them corresponded to the aggregates with a diameter above $6.3 \mathrm{~mm}$, from $47.2 \%$ to $52.6 \%$. The percentage of the eolic fraction, i.e. below $0.25 \mathrm{~mm}$, did not exceed $11.2 \%$. Similar values were obtained in the study of other integrated soil tillage sets on other soils, what is important to note, on lighter soils, i.e. loamy sands [Podsiadłowski 2005].

\section{Effect pf roller-set type}

In spite of the fact that the unit energy of tillage of the two types of rollers differed slightly, on average by $0.1 \mathrm{~kJ} . \mathrm{m}^{-2}$; for some levels of factors the effect of rollers on the percentage content of the smallest aggregates was also statistically significant. Thus, at the first date, with higher soil moisture, the change of roller types allowed reducing the amount of eroding fraction $(<0.25 \mathrm{~mm})$ by $2.6 \%$ in the surface layer, $0-5 \mathrm{~cm}$, and up to $4.2 \%$ in deeper layers. In the second period, with lower actual moisture, this effect was no longer noticeable. It can therefore be concluded that not only the type of soil but also the changing current moisture conditions in the field should be taken into account when selecting the roller to be used with a view to reducing the eolian susceptibility of the topsoil; unfortunately, these studies show that the effect will only be achieved under optimal soil moisture conditions.

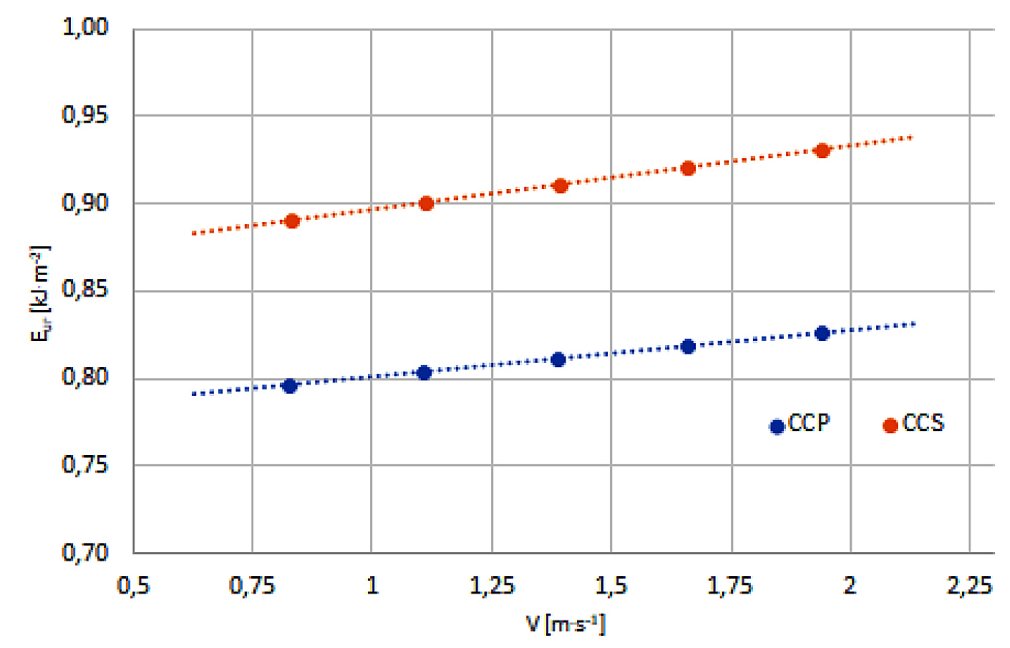

Figure 1. Relation between tillage speed $(\mathrm{V})$ and unitary rollers tillage energy $\left(\mathrm{E}_{\mathrm{UR}}\right)$ for two sets types, Campbell+Croskill platelet (CCP) and Campbell+Croskill stugged (CCS) 
Table 1. Percentage content of soil aggregate classes for two types of rollers-set, two soil moisture levels at three tillage layers (averaged for all tillage speeds)

\begin{tabular}{|c|c|c|c|c|c|c|c|c|c|}
\hline \multirow{2}{*}{$\begin{array}{c}\text { Soil } \\
\text { moisture } \\
\text { level }\end{array}$} & \multirow{2}{*}{$\begin{array}{c}\text { Tillage } \\
\text { layer }[\mathrm{cm}]\end{array}$} & \multirow{2}{*}{$\begin{array}{l}\text { Type of } \\
\text { rollers set }\end{array}$} & \multicolumn{7}{|c|}{ Mean mass fraction [\%] in size groups [mm] } \\
\hline & & & $>6.3$ & $6.3-3.15$ & $3.15-2$ & $2-0.5$ & $1-0.5$ & $0.5-0.25$ & $<0.25$ \\
\hline \multirow{6}{*}{ W1 } & \multirow{2}{*}{$0-5$} & $\mathrm{CCP}$ & 48.0 & 9.8 & 5.6 & 8.4 & 8.4 & 9.8 & 10.0 \\
\hline & & $\operatorname{ccs}$ & 49.6 & 10.0 & 5.8 & 9.0 & 9.2 & 9.0 & 7.4 \\
\hline & \multirow{2}{*}{$5-10$} & $\mathrm{CCP}$ & 46.0 & 10.2 & 5.6 & 8.2 & 8.6 & 10.4 & 11.2 \\
\hline & & $\operatorname{ccs}$ & 52.8 & 10.4 & 5.8 & 8.6 & 7.8 & 7.6 & 7.0 \\
\hline & \multirow{2}{*}{$10-15$} & $\mathrm{CCP}$ & 52.2 & 10.0 & 5.2 & 7.2 & 7.0 & 8.8 & 9.6 \\
\hline & & $\operatorname{ccs}$ & 52.6 & 10.6 & 5.6 & 8.2 & 7.2 & 8.0 & 7.8 \\
\hline \multirow{6}{*}{ W2 } & \multirow{2}{*}{$0-5$} & $\mathrm{CCP}$ & 47.2 & 10.2 & 6.0 & 9.4 & 9.4 & 9.2 & 8.6 \\
\hline & & ccs & 48.0 & 11.6 & 6.4 & 9.8 & 8.0 & 8.4 & 9.2 \\
\hline & \multirow{2}{*}{$5-10$} & $\mathrm{CCP}$ & 45.4 & 11.4 & 6.6 & 9.6 & 9.0 & 9.8 & 8.2 \\
\hline & & $\operatorname{ccs}$ & 48.0 & 10.8 & 6.8 & 9.4 & 7.6 & 8.2 & 9.2 \\
\hline & \multirow{2}{*}{ 10-15 } & $\mathrm{CCP}$ & 51.4 & 10.6 & 5.6 & 8.4 & 7.8 & 8.6 & 7.6 \\
\hline & & ccs & 50.4 & 11.0 & 5.8 & 8.6 & 7.2 & 8.4 & 8.6 \\
\hline \multicolumn{10}{|c|}{$\operatorname{LSD}_{0.05}=1.3$} \\
\hline
\end{tabular}
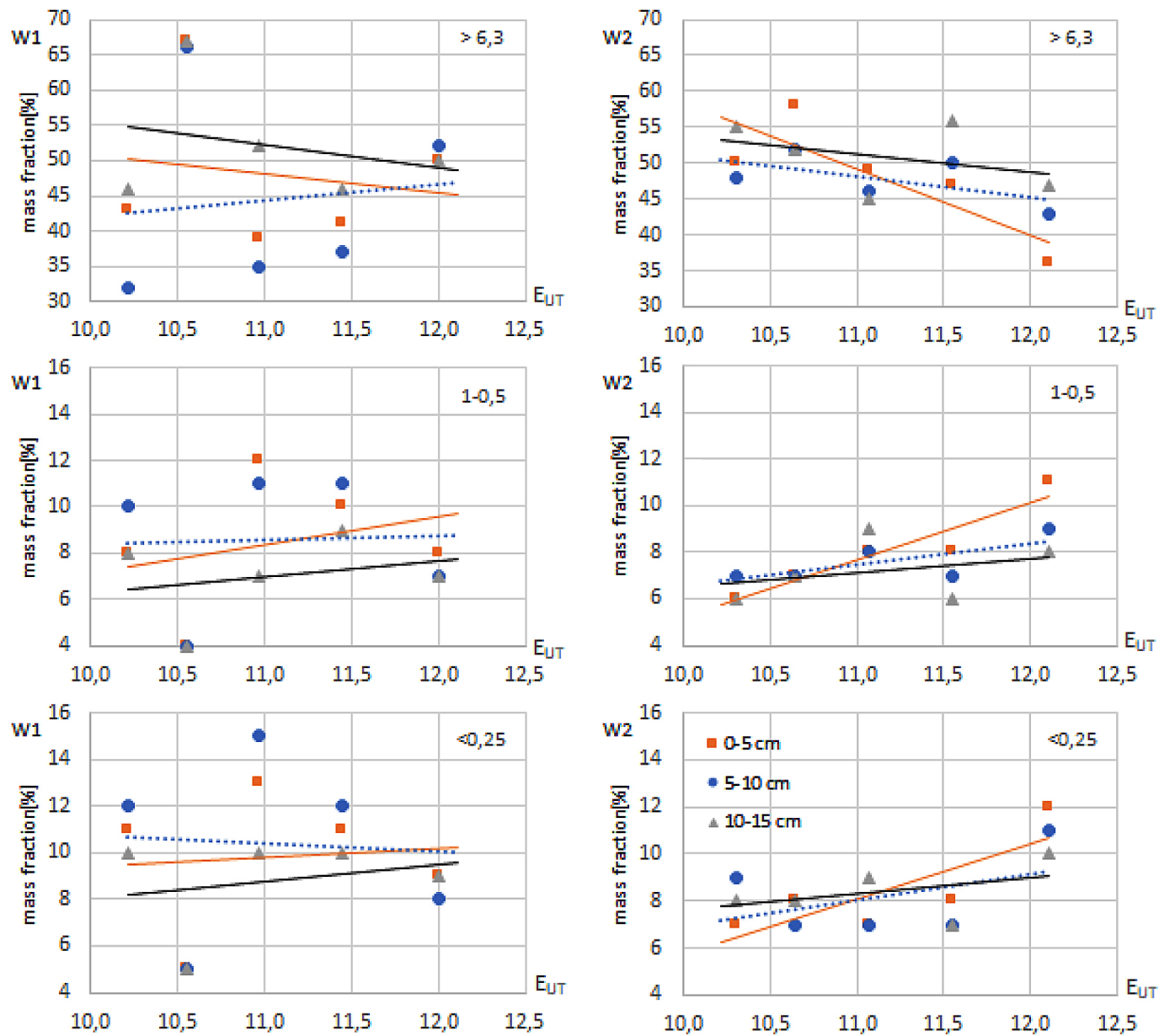

Figure 2a-f. (from left to right and up to down). Impact of unitary rollers tillage energy $\left(\mathrm{E}_{\mathrm{UR}}\right)$ for Campbell+Croskill platelet (CCP) roller set at three tillage layers $(0-5 \mathrm{~cm}, 5-10 \mathrm{~cm}$ and $10-15 \mathrm{~cm})$ and two moisture levels (on left $\mathrm{W} 1=12.5 \%$, on right $\mathrm{W} 2=8.6 \%$ ) on mass fraction of the selected three fractions of soil aggregates 

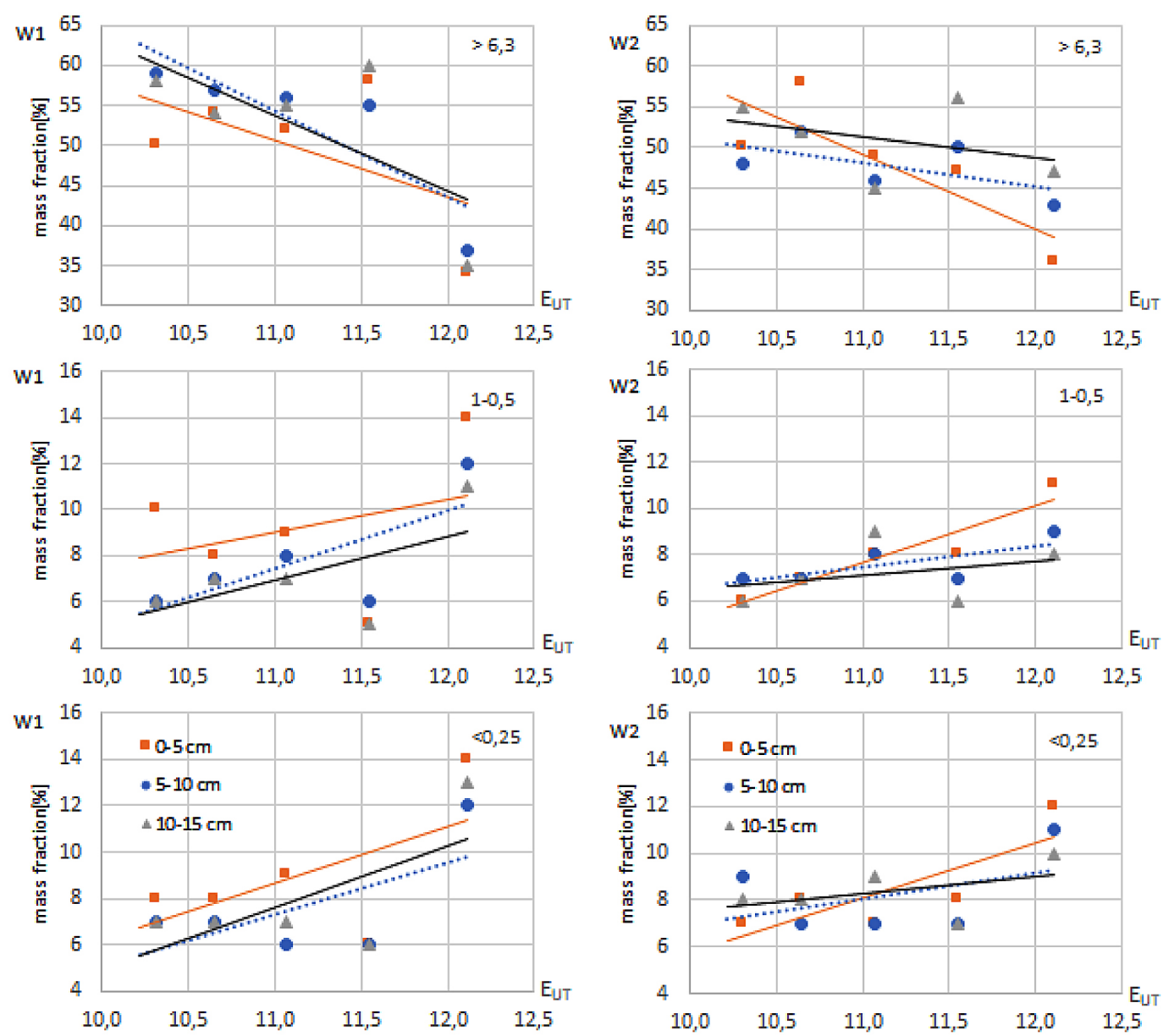

Figure 3a- f. (from left to right and up to down). Impact of unitary rollers tillage energy $\left(\mathrm{E}_{\mathrm{UR}}\right)$ for Campbell+Croskill stugged (CCS) roller set at three tillage layers $(0-5 \mathrm{~cm}, 5-10 \mathrm{~cm}$ and $10-15 \mathrm{~cm})$ and two moisture levels (on left $\mathrm{W} 1=12.5 \%$, on right $\mathrm{W} 2=8.6 \%$ ) on mass fraction for the selected three fractions of soil aggregates

\section{Effect of unitary tillage energy of rollers type}

The analysis of the effect of changing the tillage speed, and thus the unitary tillage energy, on the aggregate structure showed that it was different for aggregate groups. It also differed depending on the type of rollers used. The most significant changes were observed for the largest fractions, $>6.3 \mathrm{~mm}$ and the smallest ones, $<0.25 \mathrm{~mm}$. Therefore, in the further analysis, some examples were presented only for these fractions with the addition of an intergroup of 1-0.5 mm. In Figures 2 and 3, the effect of the roller set type on the changes in the aggregates structure as a function of unitary tillage energy can be observed.

For the Campbell+Croskill platelet (CCP) roller set, a differential effect of the roller can be observed depending on the current cultivation moisture. With higher soil moisture, the change of unit energy, in the analyzed range, had a chaotic effect on the content of aggregates, regardless of their size. At lower soil moisture, on the other hand, the influence of unit energy was already visible and with its increase, there a decrease in the proportion of the largest aggregates occurred, with an increase in the number of the smallest aggregates, $<0.25$ as well as intermediate ones. This effect was most visible in the $0-5 \mathrm{~cm}$ topsoil layer. It may suggest that this type of rollers in the case of cultivation at higher moisture may cause non-uniformity of the obtained effects, on the other hand, i.e. in the case of lower moisture, a decrease in cultivation speed will allow limiting the formation of the erosive fraction i.e. $<0.25 \mathrm{~mm}$.

With the Campbell+Croskill stugged (CCS) roller set, the process dynamics were different. With the increase of unit energy, regardless of soil moisture, there was a decrease in the content of the largest aggregates and a parallel increase in the number of intermediate and eroding 
aggregates after exceeding the speed of $1.6 \mathrm{~m} \mathrm{~s}^{-1}$. This process had the highest dynamics in the top layer, but it also occurred in deeper layers and was more intense at higher moisture. This may indicate that this type of rollers in comparison with the set of CCP rollers will be better suited, under these soil conditions, to control the tillage process in relation to its soil improving features.

\section{CONCLUSIONS}

The presented results of the study on the effect of the unitary soil tillage energy on soil aggregate structure allow concluding that it is possible to use the working speed and overloading of rollers set in integrated soil tillage trailer to manipulate the process of forming an optimal, erosion-resistant soil layer. However, it should be pointed out, that for even very similar types of roller sets the process control under different soil moisture conditions may vary and require an individual test.

\section{Acknowledgements}

The publication was funded by the Polish National Agency for Academic Exchange under the International Academic Partnerships Programme from the project "Organization of the 9th International Scientific and Technical Conference entitled Environmental Engineering, Photogrammetry, Geoinformatics - Modern Technologies and Development Perspectives".

\section{REFERENCES}

1. Czajka, M., Podsiadłowski S., Walkowiak R., and Wojciechowski T. 2010. Integrated Tillage As Anti-Erosion Soil Tillage: Research Prospects. Teka Kom. Ochr. Kszt. Środ. Przyr. - OL PAN 7, 48-54.

2. Krysztofiak, A., and Podsiadlowski S. 1998. The Method of Calculating Tillage Unitary Energy
Expendi-Ture for Prediction of Aeolian Erosion Process. In The Soil as a Strategic Resource: Degradation Processes and Conservation Measures, Tenerife. Geoforma Ed, 157-163.

3. Moraru, P. I., and Rusu T. 2012. Effect of Tillage Systems on Soil Moisture, Soil Temperature, Soil Respiration and Production of Wheat, Maize and Soybean Crops. Journal of Food, Agriculture and Environment, 10(2), 445-48.

4. Neményi, M., Mesterházi P.Á. and Milics G. 2006. An Application of Tillage Force Mapping as a Cropping Management Tool. Biosystems Engineering, 94(3), 351-57.

5. Pabin, J., Włodek S. and Biskupski A. 2008. Some environmental and production conditions concerning simplified modes of tillage, Agricultural Engineering, 1(99), 333-38.

6. Podsiadłowski, S. 2005. The integrated tillage system in wind erosion control. Acta Agrophysica, 5(1), 111-20.

7. Podsiadłowski, S. and Hagen L.J. 2000. An integrated tillage system to prevent pulverization and wind erosion of sandy soils. In: Tillage at the Threshold of the 21st Century: Looking Ahead; 15th Conference of the international soil tillage research organization fort worth, Texas, USA, Fort Worth.

8. Rusu, T. 2014. Energy efficiency and soil conservation in conventional, minimum tillage and notillage. International Soil and Water Conservation Research, 2(4), 42-49.

9. Skidmore E., Layton J. 1992. Dry-soil aggregate stability as influenced by selected soil properties. Soil Sci. Soc. Am. J., 51/1, 198-202.

10. Tabatabaeefar, A., Emamzadeh, H., Ghasemi-Varnamkhasti, Mahdi, Rahimizadeh, R. and Karimi, Mahmoud. 2009. Comparison of energy of tillage systems in wheat production. Energy, 34(1), 41-45.

11. Vural, H. and Efecan İ. 2012. An analysis of energy use and input costs for maize production in Turkey. Journal of Food, Agriculture and Environment, 10(2), 613-16.

12. Walkowiak, R., Podsiadłowski S. and Czajka M. 2017. The effect of integrated tillage of light soil on potato yields. Biometrical Letters, 54(2), 187-201. 